\title{
Solid Oxide Fuel Cell Hybrid System for Distributed Power Generation
}

\author{
Semi-Annual Technical Progress Report \\ January 2003 to June 2003
}

Faress Rahman, Dr. Nguyen Minh

July 2003

Performed under DOE/NETL Cooperative Agreement DE-FC26-01NT40779

Hybrid Power Generation Systems, LLC

19310 Pacific Gateway Drive

Torrance, CA 90502 


\section{DISCLAIMER}

"This report was prepared as an account of work sponsored by an agency of the United States Government. Neither the United States Government nor any agency thereof, nor any of their employees, makes any warranty, expressed or implied, or assumes any legal liability or responsibility for the accuracy, completeness, or usefulness of any information, apparatus, product, or process disclosed, or represents that its use would not infringe privately owned rights. Reference herein to any specific commercial product, process, or service by trade name, trademark, manufacturer, or otherwise, does not necessarily constitute or imply its endorsement, recommendation, or favoring by the United States Government or any agency thereof. The views and opinions of authors expressed herein do not necessarily state or reflect those of the United States Government or any agency thereof." 


\begin{abstract}
This report summarizes the work performed by Hybrid Power Generation Systems, LLC during the January 2003 to June 2003 reporting period under Cooperative Agreement DE-FC26-01NT40779 for the U. S. Department of Energy, National Energy Technology Laboratory (DOE/NETL) entitled "Solid Oxide Fuel Cell Hybrid System for Distributed Power Generation". The main objective of this project is to develop and demonstrate the feasibility of a highly efficient hybrid system integrating a planar Solid Oxide Fuel Cell (SOFC) and a micro-turbine. In addition, an activity included in this program focuses on the development of an integrated coal gasification fuel cell system concept based on planar SOFC technology.
\end{abstract}

This report summarizes the results obtained to date on:

$>$ System performance analysis and model optimization;

$>$ Reliability and cost model development;

$>$ System control including dynamic model development;

$>$ Heat exchanger material tests and life analysis;

$>$ Pressurized SOFC evaluation; and

$>$ Pre-baseline system definition for coal gasification fuel cell system concept 


\section{TABLE OF CONTENTS}

Disclaimer

Abstract

ii

Table of Contents

List of Figures and Tables iv

Experimental

1

Results and Discussion

1

Conclusion

18

References

18 


\section{LIST OF FIGURES AND TABLES}

Figure 1 Comparison of the number of iterations between the original and the improved model

Figure 2 System Cost Breakdown

Figure 3 The Pressure Vessel at HPGS

Figure 4 Pressure Vessel Installed at GE Global Research Center _............................... 14

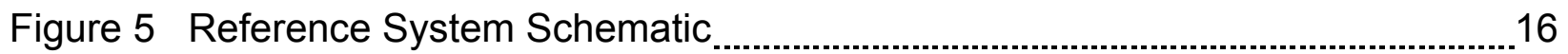

Table 1 Accuracy of Model Comparison ....................................................................... 4

Table 2 DOE Hybrid System Reliability and Availability Trade Analysis Results ............ 6

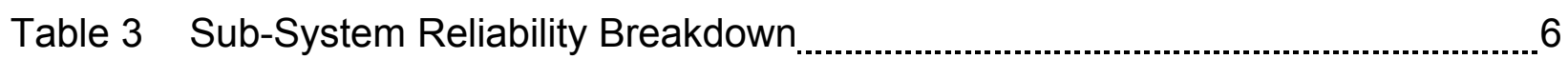

Table 4 Sub-System Availability Breakdown ……........................................................ 6

Table 5 Estimated DOE Hybrid Systems Cost $\ldots$

Table 6 Preliminary Creep Life Analysis Results .........................................................13 


\section{EXPERIMENTAL}

All experimental work currently performed on the program is contained sub-task 1A.2.1, Barrier Resolution - High Temperature Heat Exchangers and in sub-task 1A.2.2, Barrier Resolution -- Pressurized SOFC. The test procedures and the test methods used to perform the experimental work for these task has been described in previous Quarterly Technical Progress Reports.

\section{RESULTS AND DISCUSSION}

\section{TASK 1A.1 - SYSTEM DESIGN}

\subsection{SUBTASK 1A.1.1 - DESIGN CONCEPT DEVELOPMENT.}

\subsubsection{Conceptual System Design Trade Studies}

Previous reports have presented component trade studies conducted to optimize the conceptual design of the full-scale system. Four different system configurations were presented in the trade study from which one system configuration will be down selected. The down-selection will be based on system efficiency, reliability, cost, and the cost of electricity (COE). COE provides a means to trade system efficiency against reliability and cost.

The approach undertaken in the trade study consists of the following steps:

(1) The efficiency of all system concepts is analyzed as functions of system parameters;

(2) A local maximum of the resulting system efficiency function is determined for each system concept;

(3) System components are identified for each candidate system concept (some components may be common across the candidate systems);

(4) System cost and reliability are estimated;

(5) COE models are created and systems COE are estimated;

(6) The system design point is adjusted if necessary to improve system COE at the acceptable expense of system efficiency;

(7) Steps (1) through (6) are repeated until an optimized system design is found for each candidate;

(8) The system with the "best" optimized solution is down selected.

\subsubsection{Performance Analysis}

A steady state system performance model has been completed and is used as the basis for estimating power and efficiency for given component performance assumptions. The components are modeled in a sequential modular fashion using the ASPEN PLUS 
steady state platform and its thermodynamic database. This performance model has been used to analyze early system concepts for this program. However, the model execution time can exceed one hour for some model runs, severely limiting the number of runs that can be executed in support of the trade study.

In comparison, a simple cycle model developed for the DOE Solid State Energy Conversion Alliance (SECA) program using the same methodology executes in seconds and similar hybrid models developed previously for PEM fuel cells executes in minutes. Thus an effort was launched to optimize the execution time of the models for this program. This effort was necessary since the model is expected to be executed a large number of times to support the system trade study effort and subsequent sensitivity analyses.

\subsubsection{Performance Model Optimization Approach and Assumptions}

The model execution speed is determined by the design specifications and the tear streams of the performance model. Every design specifications and tear stream has an associated convergence block. The convergence blocks determine how the guesses for a tear stream or design specification manipulated variables are updated from iteration to iteration. The strategy employed for optimizing the execution time of the model includes minimizing the number of convergence blocks, which include design specifications and tear streams, and minimizing the number of iterations associated with each convergence block.

It was discovered that various solvers required several thousand iterations to converge. This is an indication of excessive looping or an extremely flat response to change. Many of these solvers were found to be related to the most inner loop centered on the fuel cell stack. Based on these findings, the simplification of the stack model was considered to reduce the overall execution time.

The system performance model uses USER blocks to model the stack. Material and energy balances are performed within these externally linked blocks, written by the user. Two USER blocks are used with a stoichiometric reactor in between to simulate the electrochemical reactions and internal reforming in the fuel cell stack. Six design specifications are used with this approach.

A new approach was taken to simplify this fuel cell stack model. Since the reactions of a fuel cell stack are similar to those of a chemical combustor, a stoichiometric reactor from the ASPEN model library was used. The electrical current drawn from the fuel cell stack is simulated by drawing a heat stream from the reactor using a "calculator" block provided by ASPEN. The fuel utilization is an input to the reactor model and used in conjunction with Faraday's law to compute the current draw. The stack voltage can be calculated from the fuel cell stack performance curve if available, or it can be simply an input to the model. The power drawn is simply calculated by multiplying the stack voltage with the total current. This approach reduces the number of solvers from seventeen to ten without any loss of model accuracy or model features. 


\subsubsection{Performance Model Optimization Results}

The reduction in the number of iterations observed in the system model is shown in Figure 1. The x-axis in Figure 1 contains the names of the various solvers used in the model. The solvers having no iterations in the "Improved" model are the ones that were deleted due to redundancy. The total number of iterations is dramatically reduced from over 42,500 to 786 and, as a result, the total execution time is reduced from over one hour to less than 2 minutes per run. The accuracy of the model is compared with that of the original model. A summary comparison is shown in Tables 3 . The maximum difference from the original is less than $0.4 \%$.

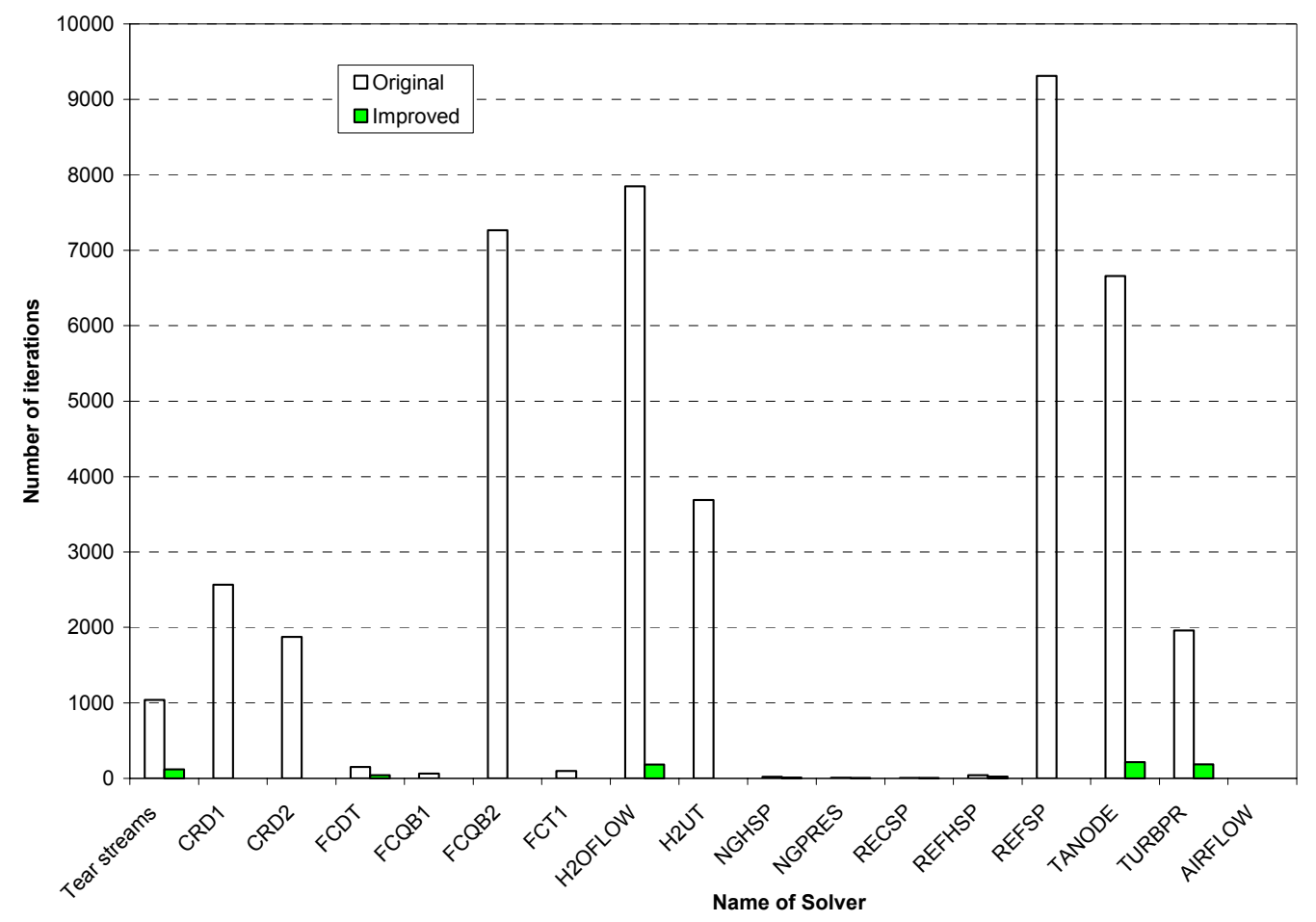

Figure 1: Comparison of the number of iterations between the original and the improved model 


\begin{tabular}{|l|l|c|}
\hline & Units & $\%$ differences \\
\hline Net System Power & $\mathrm{kW}$ & -0.35 \\
\hline System Efficiency & $\%$ & -0.31 \\
\hline Oxygen Utilization & $\%$ & 0.00 \\
\hline Fuel Utilization & $\%$ & 0.11 \\
\hline FP Steam-to-Carbon Ratio & $\%$ & 0.01 \\
\hline Reformer Heat Duty & $\mathrm{kW}$ & 0.00 \\
\hline Reformer Heater Cold Side Effectiveness & $\%$ & -0.11 \\
\hline Reformer Heater Hot Side Effectiveness & $\%$ & 0.18 \\
\hline Total SOFC Current & $\mathrm{A}$ & 0.17 \\
\hline CH4 Mole Fraction @ Anode Inlet & $\%$ & 0.12 \\
\hline Average Cell Voltage & $\mathrm{V}$ & 0.00 \\
\hline Cathode Temperature Rise, C & $\mathrm{oC}$ & -0.20 \\
\hline
\end{tabular}

Table 1: Comparison of Model Accuracy

\subsubsection{Concept Down-Selection}

The system concept down-selection will be based on system efficiency, reliability, cost, and the cost of electricity (COE). The system efficiency trades have been reported in previous reports. The development of the reliability, first cost, and COE models are reported below.

\subsubsection{System Reliability Model}

The reliability of a plant is defined as one minus the Forced Outage Factor (FOF). FOF is the fraction of time the system is forced to shut down and does not include scheduled shutdowns. The system availability is defined by the fraction of time the system is operational and includes both forced outages and scheduled outages.

Detail life, maximum and minimum repair time, and service interval data was gathered for all major components for each system concept. This data was used to estimate part reliability and availability. These estimates were then rolled up to determine the overall plant reliability for one year of continuous operation and plant availability over 10 years of operation. The number of forced shut downs as well as service maintenance intervals were also estimated to determine operation and maintenance costs. Table 2 summarizes preliminary plant level results for each concept. Table 3 and 4 provide the sub-system reliability and availability breakdown for each system concept.

Component life information was gathered from several sources. The life of the major components of the turbo-machinery was extracted from the detail life analysis reports on the Parallon75 components. The heat exchanger and the other balance of plant data were gathered from publications on previous development programs, including the advanced DOE micro-turbine program and heat exchanger programs. This data has been supported with information gathered from the Internet. The stack and fuel processor life numbers are based on current engineering knowledge and expert opinion.

The basic assumption behind the reliability model is that the components realize wear in time and the probability of failure is not constant over time. Therefore, the Weibull probability of failure is used throughout. The Weibull slope for all components in this 
study is between 1 and 4 , indicative of increasing failure rates. In such cases, it has been shown in practice that a scheduled replacement may be cost effective. Consequently, in availability calculations when a maintenance interval is identified for a certain component, the component is assumed to be replaced with a new unit and the component life used in the overall plant reliability is assumed to be reset.

A simple rule of thumb was used to estimate the life of high temperature components and also the temperature dependence of their life. The nominal life of these components were assumed to reduce to half their original life for every 25 degree $\mathrm{F}$ increase in operating temperature. This rule of thumb assumes no change in materials from the baseline case and is based on expert judgment.

The availability spreadsheet uses a Monte Carlo simulation to estimate the expected plant availability, the standard deviation of the availability calculation, and the expected number of forced and scheduled plant outages. This analysis assumes a normal probability distribution for the life (i.e. a Weibull distribution with beta set at 1.0) and repair time duration. 


\begin{tabular}{|c|c|c|}
\hline $\begin{array}{c}\text { System Concept } \\
\text { No. }\end{array}$ & Reliability & Availability \\
\hline 1 & $86 \%$ & $88 \%$ \\
\hline 2 & $92 \%$ & $89 \%$ \\
\hline 3 & $86 \%$ & $88 \%$ \\
\hline 4 & $92 \%$ & $89 \%$ \\
\hline
\end{tabular}

Table 2: DOE Hybrid System Reliability and Availability Trade Analysis Results

\begin{tabular}{|c|c|c|c|c|c|c|}
\hline & & \multicolumn{5}{|c|}{ Sub-System Reliability } \\
\hline Concept & $\begin{array}{c}\text { Total } \\
\text { System }\end{array}$ & $\begin{array}{c}\text { Fuel } \\
\text { Processing }\end{array}$ & Microturbine & $\begin{array}{c}\text { Power } \\
\text { Electronics }\end{array}$ & SOFC & BOP \\
\hline $\mathbf{1}$ & $\mathbf{8 5 . 7 3 \%}$ & $93.00 \%$ & $99.74 \%$ & $100.00 \%$ & $99.28 \%$ & $93.09 \%$ \\
\hline $\mathbf{2}$ & $\mathbf{9 1 . 8 3 \%}$ & $93.00 \%$ & $99.74 \%$ & $100.00 \%$ & $99.28 \%$ & $99.72 \%$ \\
\hline $\mathbf{3}$ & $\mathbf{8 5 . 6 5 \%}$ & $92.92 \%$ & $99.74 \%$ & $100.00 \%$ & $99.28 \%$ & $93.10 \%$ \\
\hline $\mathbf{4}$ & $\mathbf{9 1 . 7 5 \%}$ & $92.92 \%$ & $99.74 \%$ & $100.00 \%$ & $99.28 \%$ & $99.73 \%$ \\
\hline
\end{tabular}

Table 3: Sub-System Reliability Breakdown

\begin{tabular}{|c|c|c|c|c|c|c|}
\hline & & \multicolumn{5}{|c|}{ Sub-System Availability } \\
\hline Concept & $\begin{array}{c}\text { Total } \\
\text { System }\end{array}$ & $\begin{array}{c}\text { Fuel } \\
\text { Processing }\end{array}$ & Microturbine & $\begin{array}{c}\text { Power } \\
\text { Electronics }\end{array}$ & SOFC & BOP \\
\hline $\mathbf{1}$ & $\mathbf{8 8 . 0 2} \%$ & $95.94 \%$ & $97.46 \%$ & $99.53 \%$ & $98.42 \%$ & $96.67 \%$ \\
\hline $\mathbf{2}$ & $\mathbf{8 9 . 2 4 \%}$ & $95.94 \%$ & $97.46 \%$ & $99.53 \%$ & $98.42 \%$ & $97.89 \%$ \\
\hline $\mathbf{3}$ & $\mathbf{8 7 . 5 3 \%}$ & $95.32 \%$ & $97.46 \%$ & $99.53 \%$ & $98.42 \%$ & $96.79 \%$ \\
\hline $\mathbf{4}$ & $\mathbf{8 8 . 7 5} \%$ & $95.32 \%$ & $97.46 \%$ & $99.53 \%$ & $98.42 \%$ & $98.01 \%$ \\
\hline
\end{tabular}

Table 4: Sub-System Availability Breakdown

\subsubsection{System Cost Model}

The first cost of the overall system for each system concept was assessed in the cost roll-up model. Cost estimates have been made on all major components including the micro-turbine, stack, fuel processor, and the Balance-of-Plant (BOP). The BOP includes the thermal management sub-system, the air, fuel and water delivery subsystems, and the controls and power electronics subsystems.

For sub-systems requiring significant technology development, a bottom-up cost model approach was used. For example, a dedicated stack cost model was constructed with the capability to conduct sensitivity analyses. The cost model itemizes the cost into four major components: materials, labor, equipment, and facilities costs. The stack cost model uses Monte-Carlo simulations on the overall stack cost, based on given cost probability distributions for the different cell and stack components. The fuel processor 
cost was estimated to be the same as that of the stack. This is consistent with TIAX estimation. $^{1}$

Cost estimates for sub-systems containing, to a large degree, currently available technology were derived from quotes obtained from vendors. Adjustments were subsequently made to these quotes to ensure a consistent cost basis. These adjustments were based on engineering judgment. Cost information contained in vendor catalogs were also used as a guide. This approach was used on the microturbine, air, fuel and water delivery subsystems and other balance-of-plant (BOP) components. Quotes from vendors, compiled previously for all Parallon 75 microturbine, were used as the basis for many of the BOP parts.

All cost estimates have been based on a production volume of 500 units/year or approximately $250 \mathrm{MW}$ per year. This volume is based on preliminary estimates of the market size for systems rated less than $1 \mathrm{MW}$.

Preliminary results from the cost model are summarized in Table 5 . The cost breakdowns for each system concept is shown in Figure 2.

\begin{tabular}{|c|c|c|c|c|}
\hline SYSTEM & $\begin{array}{c}\text { NET POWER } \\
\mathbf{( k W )}\end{array}$ & $\begin{array}{c}\text { SOFC POWER } \\
\mathbf{( k W )}\end{array}$ & $\begin{array}{c}\text { EFFICIENCY } \\
\mathbf{( \% )}\end{array}$ & $\begin{array}{c}\text { Cost } \\
\mathbf{( \$ / k W )}\end{array}$ \\
\hline CONCEPT 1 & 439 & 356 & 61.2 & 572 \\
\hline CONCEPT 2 & 411 & 343 & 59.9 & 628 \\
\hline CONCEPT 3 & 352 & 280 & 59.2 & 631 \\
\hline CONCEPT 4 & 450 & 400 & 64.1 & 637 \\
\hline
\end{tabular}

Table 5: Estimated DOE Hybrid Systems Cost

\footnotetext{
1 "Scale-up Study of 5 KW SECA Modules to a $250 \mathrm{~kW}$ System”, TIAX LLC Final Report to DOE/NETL, Reference: 74313, June 10, 2002
} 

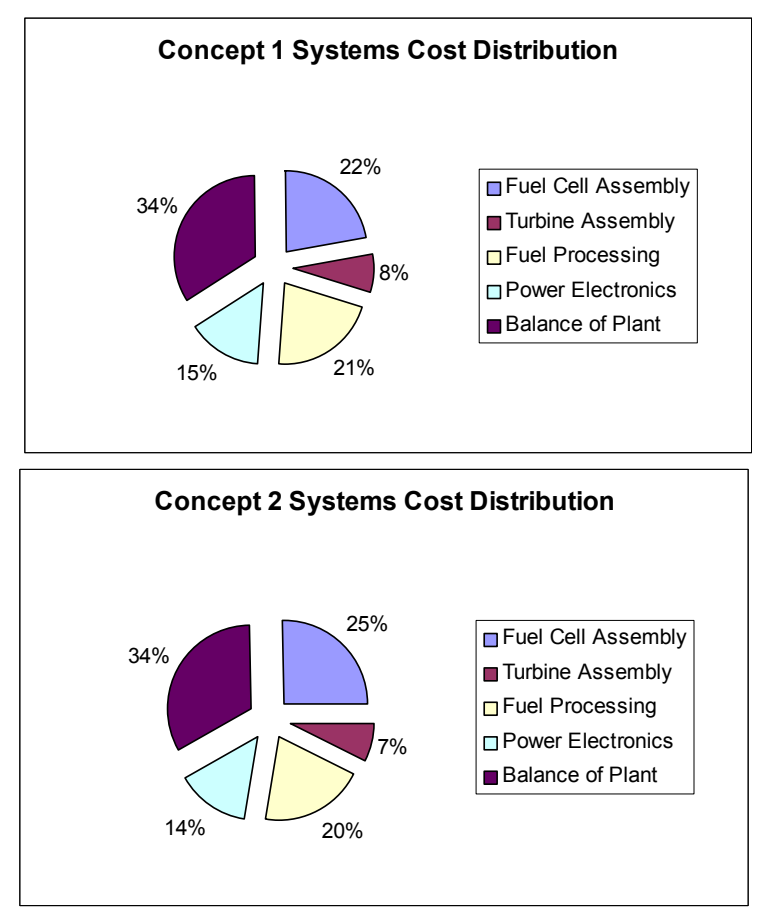

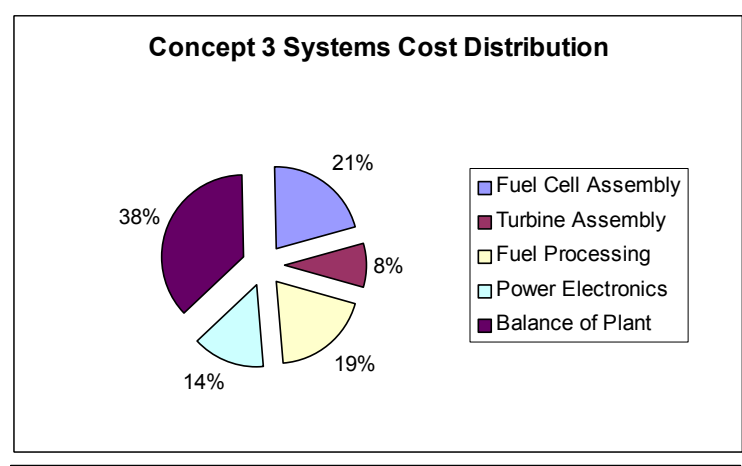

Concept 4 Systems Cost Distribution

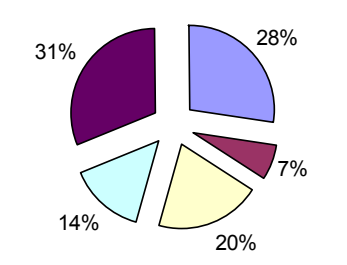

Figure 2 System Cost Breakdown

\subsubsection{System Cost of Electricity Model}

The Cost of Electricity (COE) model integrates the performance, reliability, and the cost models. COE is composed of three parts: the cost of fuel, capital cost, and the cost of operation and maintenance.

The fuel cost is mainly affected by the efficiency of the system and the availability of the plant. The capital cost consists of the system manufacturing cost and the installation and start-up costs. Operation and maintenance cost are estimated directly from the availability analysis, described above.

For the COE model, it is estimated that the first cost of a plant from the perspective of the customer (otherwise called installed cost) is about twice the manufacturing cost, and the operation and maintenance cost of a plant is about $10 \%$ of the installed cost.

The construction of the COE model is currently in progress. Complete results are expected in the next report.

\subsubsection{Control System}

The control system development focused on three primary areas during this reporting period:

$>$ Dynamic System Modeling

$>$ Conceptual Control System Design

$>$ Control System Trade Studies 
The dynamic system model and the conceptual control system design are key tools that are necessary for conducting the control system trade studies. The dynamic system model provides a transient representation of the hybrid fuel cell system so that system operation can be fully understood and dynamic issues identified early through simulation. The conceptual control system design defines the way that the system will be controlled and provides the basis for control system trade studies. The results of the control system trade studies will feed into the overall steady state system design with the goal of moving the overall system design to a configuration that is inherently more controllable.

\subsubsection{Dynamic System Model}

The dynamic system model is a key tool used in developing the control strategy for the hybrid system. Simulations at both the sub-system and system level continued to examine the dynamic interactions within the system to develop a better understanding of the dominant dynamic characteristics of the system. This work continues to reveal the sensitivities many different control parameters.

The pressure and flow dynamics are extremely challenging when dealing with a small turbine and large gas volumes within the system. These dynamics are important to understand when devising a control strategy that ensures the thermal protection of the stack and sufficient reactant flow to the stack to support the electrochemical reaction in the fuel cell stacks. On the compressor side, these dynamics may lead to compressor surge if they are not adequately accounted for within the control system.

Stack inlet conditions, and therefore stack performance, are sensitive to many different control parameters such as gas composition, fuel utilization, and air utilization. The entire hybrid system must be well coordinated in order to control and maintain the stack inlet temperatures, pressures, and flows to provide the necessary performance from the fuel cell. Low fuel utilization at the fuel cell can lead to over-temperature problems at the downstream components. This removes the ability to independently lower the fuel utilization as a way to protect the fuel cell from transients.

Preliminary results from the dynamic system model have been obtained using open loop commands for the various effectors in the system. The feedback controls are currently being integrated into the dynamic system and tuned for stable operation of the system at the desired set-points for various loads. The sensitivity of the system to various dynamic behaviors has been observed. Specifically, the flow and pressure variables converge quickly to steady state values, whereas the temperature values operate on a longer time scale. Although the temperature values are lower than would be anticipated during normal operation, it is expected that these values will reach their set-points as the active controls are integrated and tuned.

Beyond understanding the dominant dynamics of the system, the dynamic modeling efforts focused on verifying the steady state results from the dynamic model and improving the execution speed of the dynamic model. 


\subsubsection{Dynamic System Model Verification}

During this reporting period a study was conducted to verify that the steady state predictions from the dynamic system model compare well with the steady state Aspen model results. This effort determines the confidence that should be placed in the conclusions drawn from the dynamic system model results.

To verify the individual dynamic component models, simulations were set up and performed for each component in the hybrid system. In these studies, each component model was run in the Matlab/Simulink environment and their steady state output was compared to the results generated by the Aspen steady state simulation. The overall performance of the set of system component models was satisfactory with differences usually less than $5 \%$ and the largest error being $14 \%$.

The large disparities are currently being addressed by tuning of the heat exchanger performance maps. The $11 \%$ discrepancy in the stack power is likely due to the $8.3 \%$ difference in the stack outlet temperature. The reason for this difference is still under investigation, but is likely due to the dissimilarities between the computational schemes used by the dynamic model and the steady state model for internal reforming. Ideally all of the differences between the steady state and dynamic models would be zero, but the current performance of the dynamic model is sufficient to proceed with the control system trade studies.

Integration of the various individual components into a dynamic system model has proven to be a significant challenge. A number of system couplings have led to a stiff simulation with a high degree of numerical complexity. Efforts are on-going to eliminate these numerical issues and improve the predictions of the dynamic component models.

\subsubsection{Dynamic System Model Execution Speed}

The dynamic system modeling work focused primarily on reducing the execution time required for running the overall dynamic system model. Several bottlenecks in the simulation were identified and removed. Many of the numerical issues are due to the physics included in the system model having several different time-scales. These stiffness issues can only be truly eliminated by making simplifying assumptions and reducing the fidelity of the predictions from the dynamic model. The remainder of the numerical issues are due to calculation methods and non-linearities. Updated turbomachinery models were created to remove numerical issues associated with the steep gradients on the pressure versus flow versus speed maps. This improvement will be integrated into the dynamic system model during the next reporting period. Work continues on improving execution time using component, subsystem, and system level models as appropriate. The full system model execution speed is currently equivalent to real-time. Due to the complexity of the proposed system, dynamic system model execution speed will continue to be a challenge throughout Phase 1 of the program and is expected to carry on into Phase 2. To accommodate this, simplified models are being employed in the control system trade studies with the full dynamic system model used primarily to verify the simplifying assumptions and for integration of the control system design. 


\subsubsection{Conceptual Control System Design}

The primary work on the conceptual control system design was around implementing the feedback controls in the dynamic system model and fine-tuning the control parameters to maintain stable operation. The structure and function of the control system remained primarily unchanged during this reporting period.

The preliminary control and electrical system requirements were defined and documented. This effort translated the top-level system requirements given in the product specification to more detailed requirements needed for control system design. Where possible, the product specification values were used directly to set the requirements. If the product specification did not address a requirement needed for the control or electrical system design, the needed requirement was assumed and then negotiated with the system and component teams.

\subsubsection{Control System Trade Studies}

The objective of the control system trade studies is to develop a better understanding of the controllability of the proposed system and develop a more complete control strategy. This study will identify the key controllability issues for each of the four considered systems. It will establish controllability goals and objectives that will become the basis for evaluating the impact of the system design on controllability. Further, the trades will prioritize the controllability issues based on the system requirements and will provide general guidance or key design parameters for how to address the top ranked issues. These trade studies will provide feedback to the overall system design so that it can be adjusted to a more controllable configuration. Finally, this effort will establish and validate the basic tools that will be used to design the conceptual and demonstration control systems in subsequent phases of the program.

The control system trade studies were prioritized using a structured approach, called Quality Function Deployment (QFD). This approach uses the top-level program and system requirements as criteria to rank the impact of the different trades on the study. The top-ranked trades will be addressed first. Those trade studies that are not concluded during Phase 1 of the program are expected to be addressed in greater detail during the control design efforts in Phase 2 and 3 of the program.

Each trade study investigates the impact on the top-level system metrics, called Criticalto-Quality (CTQ). These CTQ's are consistent with the system trade studies, described above, namely performance, cost, and reliability. The cost metric is impacted through the cost of the controller, sensors, actuators, and any additional components that are necessary for control of the system. Likewise, the performance metric is measured through its impact on system power output, system efficiency, the dynamic response of the system, the design margin maintenance, and stability of the system. Finally, the reliability metric is impacted by constraints on the components and the ability of the system to respond to performance disturbances. 


\section{TASK 1A.2 - TECHNICAL BARRIER RESOLUTION}

\subsection{SUBTASK 1A.2.1 - HIGH TEMPERATURE HEAT EXCHANGERS}

The objective of this task is to develop, design, fabricate, and test a high temperature heat exchanger capable of operating with high-temperature exhaust gases to heat up air before it is introduced into the fuel cell stack. Prior reports have outlined the design and construction of a demonstration heat exchanger for testing. The analysis of a high temperature heat exchanger for pressure containment and creep life was conducted in this reporting period. This analysis has been supported with oxidation tests on coupons of representative high temperature materials.

\subsubsection{Oxidation Tests}

Sixty coupon samples were prepared and placed in three furnaces at different temperatures: $1350^{\circ} \mathrm{F}, 1475^{\circ} \mathrm{F}$, and $1650^{\circ} \mathrm{F}$. The tested coupons are made out of Inconel 625 and Haynes 230 rods. The tested samples are scheduled for removal from furnaces at different exposure time from 250 to 5000 hours. Six samples were removed from furnaces for intermediate analysis.

At low exposure times the oxidation and depletion layers are quite small, as expected. However, the oxidation effect is higher at higher temperature for both materials. Also, the oxidation effects are more pronounced for Inconel 625 compared to Haynes 230. Analysis of these test samples will be reported shortly.

\subsubsection{Heat Exchanger Tests}

A series of performance tests is planned to be conducted with an Inconel heat exchanger. The heat exchanger is expected to be received in the next reporting period. A test plan has been developed to include pressure drop and thermal performance measurements at various design and off-design operations.

\subsubsection{Heat Exchanger Life Analysis}

A life assessment analysis was initiated to evaluate the life of the heat exchanger at the system level thermal requirements. The analysis includes structural analysis for pressure containment and creep life assessment. The preliminary analysis was completed for the heat exchanger core fins and manifolds. The creep life to rupture was computed for cress 18-2 fins as well as Inconel fins based on the stress of $3.5 \mathrm{ksi}$ in the hot passage. The results are shown in Table 6 . The Inconel 625 fins are expected to dramatically improve life of heat exchanger. In this case, the life of the core would no longer be driven by stresses in the hot fins. 


\begin{tabular}{|l|c|c|}
\cline { 2 - 3 } \multicolumn{1}{c|}{} & $18-2$ material & Inconel 625 \\
\hline Rupture, LMP [2] & 40.5 & 50.1 \\
Temperature & $1650^{\circ} \mathrm{F}$ & $1650^{\circ} \mathrm{F}$ \\
Time (hours) & $\mathbf{0 . 1 6}$ & $\mathbf{5 5 4 7}$ \\
\hline
\end{tabular}

Table 6: Preliminary Creep Life Analysis Results

2.2 SUBTASK 1.A.2. 2 - PRESSURIZED SOFC

Two identical pressure vessels that can accommodate larger SOFC stack testing up to pressures of 4 atmospheres were transferred from Honeywell to Hybrid Power Generation Systems (HPGS) in March (Figure 3). One of the vessels that had previously been assembled was shipped to GE's Global Research Center. These pressurized vessels are described in greater detail in Section 2.2.1.

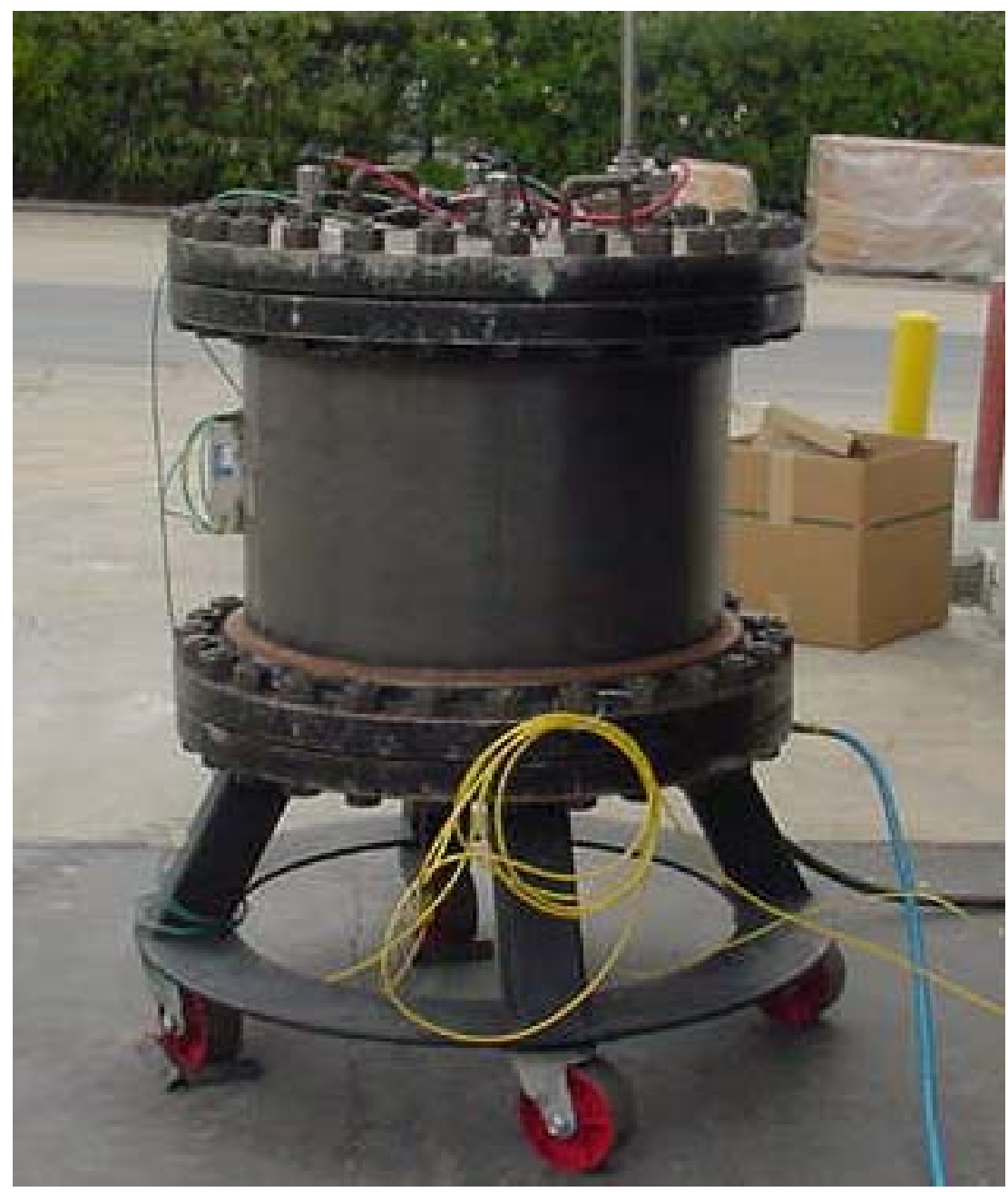

Figure 3. The Pressure Vessel at HPGS 
Bake out of the pressure vessel was completed. However, no further pressurized SOFC testing has been completed at HPGS due to construction delays at HPGS.

Recent efforts at GE Global Research Center (GRC) have been dedicated to receiving, installing and performing shakedown tests on the second pressure vessel. The diagnostic checkout cumulated in a pressurized test on a single cell module at 4 atm. Results of this test is provided in Section 2.2.2.

\subsubsection{Pressure Vessel Test Stand}

The pressure vessel is a stamped vessel rated for 60 psig and a skin temperature of $200 \mathrm{~F}$ and is shown in Figures 3 and 4. It is made from carbon steel and has an outer diameter of 28" and an overall height of 24". The internal hot zone is 12 inches high by 10 inches in diameter. The furnace is located within the pressure vessel and is held in place by a steel plate that is welded to the bottom of the pressure vessel. Four electrical connections for the furnace protrude through the top of the pressure vessel and are connected to the controller. The leads are isolated from the pressure vessel by using ceramic insulators. The pressure vessel is also equipped with a pressure relief device.

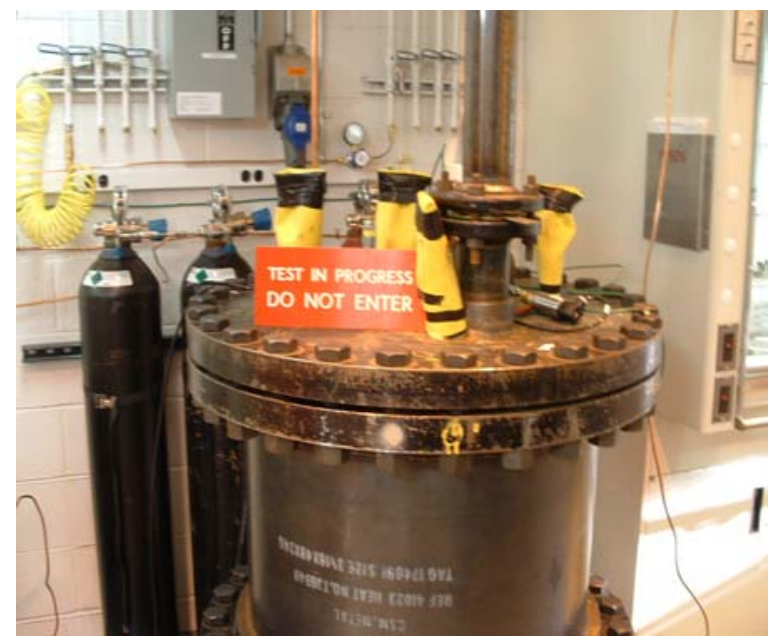

Figure 4: Pressure Vessel Installed at GE Global Research Center

Bake-out was performed on the pressure vessel prior to testing. The vessel was initially baked out twice at 1000 degree $F$ and $1 \mathrm{~atm}$. The vessel was then taken apart, cleaned, re-assembled and baked out at the same temperature and $4 \mathrm{~atm}$. In addition the pressure vessel skin temperature was monitored at multiple locations during testing and all temperature readings remained at or below 135 degree $F$.

Upon completion of the bake-out cycles, single cell modules were tested to validate the test stand functionality. The pressure vessel was brought to operating temperature using the standard thermal ramp cycle. Polarization curves were taken at different pressure levels on the single cell module.

During the diagnostic checkout phase many issues arose. Shorting issues were caused by the liberal use of nickel anit-sieze on pipe fittings that provided the pass through for 
thermocouples, voltage leads, current leads, and the reactant feed tubes. In order to resolve this all of the pipe fittings and the associated ceramic pass throughs were removed and cleaned to remove the anti seize residue. In addition, pre-mature failure of the nickel rupture disk occurred and the reason for this is currently under investigation.

Overall, the checkout tests provided needed run time of the pressure vessel test assembly prior to starting performance testing. During the final checkout test, a single cell module was able to operate up to $4 \mathrm{~atm}$ and $800 \mathrm{C}$ without incident.

\subsubsection{Pressurized Testing}

Constant flow polarization curves at $1,2,3$, and 4 atm were taken on a single cell module to calibrate the test stand. Data was taken with a fuel composition of $25 \%$ hydrogen and $75 \%$ nitrogen. As expected, performance of the single cell module increased with elevated pressure.

3 TASK 1A.4 - COAL BASED SYSTEM STUDY

\subsection{SUBTASK 1A.4.1 - PRE BASE LINE SYSTEM.}

The objective of this task is to integrate pressurized planar SOFC modules to an existing Integrated Gasifier Combined Cycle (IGCC) power plant to evaluate potential benefits of the SOFC integration. Specifically, the system level study was limited to simple integration of the SOFC modules to determine the pre-baseline configuration, to be used as a benchmark for future work. Subsequent efforts will be devoted to the optimization of this system.

Many potential IGCC configurations were considered. An oxygen blown gasifier, which powers two GE 6FA gas turbines and a bottoming steam turbine, producing $245 \mathrm{MW}$ of power was chosen as the reference configuration for the pre-baseline configuration. This system is shown in Figure 5. The integration of the fuel cell involved the elimination of one gas turbine, replacing it with a SOFC system of similar capacity ( $\sim 90 \mathrm{MW})$. The air blown systems were not considered since historical data indicates they are significantly more expensive due to the size of the equipment.

The analysis of the system assumed current SOFC technology, with a pressurization limit of 4 atmospheres and a temperature limit of $775 \mathrm{deg} \mathrm{C}$. A sour gas shift reactor was added to the gasified prior to sulfur removal, using a conventional amine process. This enables the bulk of the $\mathrm{CO}$ to be converted to hydrogen enhancing the potential performance of the SOFC fuel cell modules. A zinc guard bed was added to the processed syngas going to the fuel cell modules. This syngas stream was heated to meet the stack requirements prior to entering the stack. On the air side, the maximum possible extraction from the GE 6FA GT was assumed. However, this airflow is far too low for removal of the heat from the SOFC modules and available fuel. Consequently, additional low-pressure compressors were added to the system to augment the flow to the SOFC stacks.

This pre-baseline system is estimated to have a plant thermal efficiency of $43.6 \%$ (net, $\mathrm{HHV}$ ) compared to the reference IGCC configuration efficiency of $40.8 \%$ (net, HHV). 
The plant output was $95 \mathrm{MW}$ from the fuel cell, $95 \mathrm{MW}$ from the gas turbine and $40 \mathrm{MW}$ from the steam turbine.

A topical report detailing the results of this analysis is being prepared.

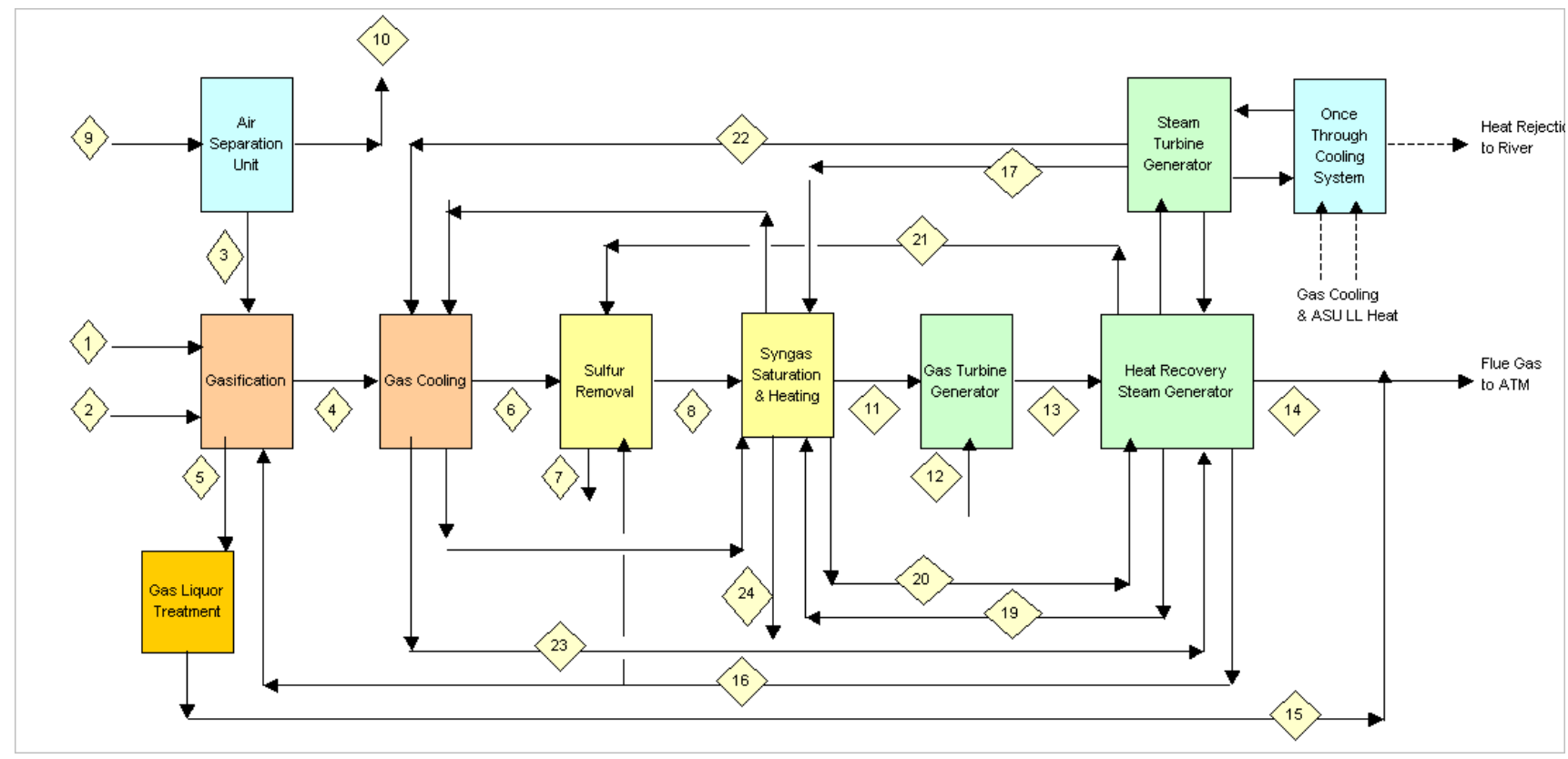

Figure 5: Reference IGCC System Schematic

\subsection{2 SUBTASK 1A.4.2 BRAIN STORMING OF BASELINE SYSTEM CONFIGURATIONS}

The efficiency of the IGFC system is a strong function of the following parameters:

(a) SOFC current density;

(b) SOFC operating temperature;

(c) Overall system fuel utilization;

(d) SOFC operating maximum temperature;

(e) SOFC operating pressure

(f) Overall system integration and optimization

The overall objective of the baseline system brainstorming was to arrive at potential plant configurations that maximizes the plant performance. This brainstorming activity is limited to item (f) in the above. Theoretically, the use of all of the syngas produced by the gasifier in the SOFC system should improve the plant performance significantly.

Successful integration requires that the gasifier be integrated with the SOFC subsystem and the bottoming combined cycle in a manner to further enhance the performance of the power plant. This integrated gasifer SOFC combined cycle is referred to in this study as the Integrated Gasification Fuel Cell (IGFC) baseline system configuration. 
For the baseline system brain storming, the focus was limited to the stack configurations that enable successful integration of the system.

Since the overall plant performance is significantly enhanced by the electrochemical consumption of the fuel rather than its combustion. The firing temperature of the gas turbine is not considered to be a significant driver to the overall all plant performance. This is further reinforced by the fact that the energy recovery can be accomplished in the gas turbine or the bottoming steam turbine. Consequently, the stack configurations outlined here have the potential to produce the highest possible system efficiencies by reducing the air requirement to the SOFC system and also reducing the overall pressure drop in the stacks.

A basic SOFC power module configuration was developed that provides about $5 \mathrm{MW}$ of power in a single module with minimum pressure drop. The objective was to maintain the stack inlet air temperature while minimizing the plant air usage. Several integration options were considered.

In addition each integration option has the potential to be driven by a single or multiple gas turbines. Very large compressors and turbines are required if a single gas turbine configuration is chosen. This has the potential for higher gas turbine performance and lower cost. However, the manifold losses are expected to be significantly higher for this configuration. This issue will be specifically addressed in subsequent tasks as all configurations are expected to benefit by this approach.

Similarly, the heat integration to the steam turbine is expected to have a significant impact based on the quality of the heat available. To this extent it was decided that an assessment of the overall steam turbine performance as a function of the quality of heat will be used for the preliminary evaluation, and detailed evaluation and optimization of the system performance will be made in subsequent tasks after the down select of the baseline configuration.

Currently, the single module performance for a given gasifier output fuel composition and gas turbine performance is under evaluation for overall SOFC power module performance, plant air usage, gas turbine cycle output, and quality of heat to the bottoming steam cycle. Based on the output of this analysis the configuration down select will be made. This is expected to take into consideration the potential for carbon dioxide sequestration.

Modeling of the various options is in progress. 


\section{CONCLUSION}

The following activities have been carried out during this reporting period. The results from these activities are summarized in this report.

$>$ Optimization of the steady state system performance model

$>$ Construction of the system cost and reliability rollup models

$>$ Control system analysis and trade studies

$>$ Dynamic system model verification

$>$ Testing of high temperature heat exchanger material coupons

$>$ High temperature heat exchanger pressure containment and creep life analysis

$>$ Setup of pressurized SOFC testing facilities, including two pressurized vessels

$>$ Integrated coal gasification and SOFC pre-baseline system configuration analysis.

Work in these areas is continuing.

\section{REFERENCES}

"Scale-up Study of 5 KW SECA Modules to a $250 \mathrm{~kW}$ System", TIAX LLC Final Report to DOE/NETL, Reference: 74313, June 10, 2002. 